\title{
Degradabilidad y estimación del consumo de forrajes y concentrados en alpacas (Vicugna pacos)
}

\author{
DEGRADABILITY AND ESTIMATION OF THE INTAKE OF FORAGES AND CONCENTRATES IN \\ ALPACAS (Vicugna pacos)
}

\author{
Alfonso Cordero F. ${ }^{1}$, José Contreras P. ${ }^{1,2}$, James Curasma C. ${ }^{1}$, Miguel Tunque Q. ${ }^{1}$, \\ Daniel Enríquez Q. ${ }^{1}$
}

\section{Resumen}

\begin{abstract}
El estudio tuvo como objetivo evaluar los parámetros cinéticos de la degradación in situ de la materia seca (MS), proteína cruda (PC) y la estimación del consumo mediante ecuaciones de predicción de MS de forrajes y alimentos concentrados en alpacas Huacaya (Vicugna pacos). Se trabajó con ensilado de maíz chala (Zea mays L) sin y con $1 \%$ de urea, cebada (Hordeum vulgare $\mathrm{L}$ ), avena (Avena sativa $\mathrm{L}$ ), salvado de trigo (Triticum aestivum L) y raspa de papa (Solanum tuberosum). Los alimentos (5 $\mathrm{g}$ en base seca) fueron colocados en sacos de nylon e incubados durante $0,6,12,24,48$ y 76 horas en el primer compartimento estomacal de dos alpacas fistuladas. Se analizó la MS y la PC de los residuos de los sacos. La MS y la PC del salvado de trigo y de la raspa de papa presentaron potenciales de degradación elevados, así como la MS y la PC de la avena. Se destaca la mayor fracción no degradable de la PC del maíz chala sin y con urea y, por tanto, una menor degradabilidad de la PC. Las estimaciones del consumo por las alpacas generadas por las ecuaciones de tres estudios no son adecuadas a los alimentos en estudio.
\end{abstract}

Palabras clave: tasa de degradación in situ; parámetros cinéticos; alpaca Huacaya; estimación del consumo

\section{Abstract}

The objective of the study was to evaluate the kinetic parameters of in situ degradation of dry matter (DM), crude protein (PC) and the estimation of DM intake of forages and concentrated feeds by prediction equations in Huacaya alpacas (Vicugna pacos). The study included maize silage (Zea mays L) without and with 1\% urea, barley (Hordeum

\footnotetext{
${ }^{1}$ Laboratorio de Nutrición Animal y Evaluación de Alimentos, Departamento Académico de Zootecnia, Facultad de Ciencias de Ingeniería, Universidad Nacional de Huancavelica, Perú

${ }^{2}$ E-mail: joselcpunh123@hotmail.com
}

Recibido: 10 de agosto de 2017

Aceptado para publicación: 15 de enero de 2018 
vulgare $\mathrm{L}$ ), oats (Avena sativa $\mathrm{L}$ ), wheat bran (Triticum aestivum $\mathrm{L}$ ) and potato scrap (Solanum tuberosum). The feeds ( $5 \mathrm{~g}$ on dry basis) were placed in nylon bags and incubated during $0,6,12,24,48$ and 76 hours in the first stomach compartment of two fistulated alpacas. The MS and the PC of the residues in the nylon bags were analyzed. The DM and PC of wheat bran and potato scrap showed high degradation potential, as well as MS and PC of oats. The highest non-degradable fraction of the PC of the maize with and without urea is highlighted and, therefore, PC showed lower degradability. Estimates of consumption by alpacas generated by the equations of three studies are not adequate for the feeds under study.

Key words: in situ degradation rate; kinetic parameters; alpaca Huacaya; estimation of consumption

\section{INTRODUCCIÓN}

La productividad animal está directamente relacionada con la calidad de la alimentación suministrada a los animales; sin embargo, la estacionalidad de la oferta de alimentos (escasez en los meses más fríos y secos del año y abundancia en la época de lluvias), así como la baja producción y calidad de los pastos perjudica la explotación de la ganadería en la sierra del Perú. Según Gomide (2004), la cualidad de los alimentos está dada por su valor nutritivo, representado por su composición química, digestibilidad de sus nutrientes y consumo de materia seca, así como por el desempeño productivo. Además, la alimentación animal depende de cuatro factores importantes referidos a los sistemas de formulación de dietas: exigencias nutricionales, cantidad de nutrientes ingeridos por el animal, composición química y degradabilidad o digestibilidad de la materia seca y de los nutrientes (Spíndola et al., 2016).

Para la evaluación de la digestibilidad de especies forrajeras y de residuos agroindustriales, especialmente de la proteína, se desarrollaron métodos in situ con bolsas porosas no degradables que permitían colocar muestras de alimento por tiempos definidos en el rumen de animales canulados, y así observar el desaparecimiento de su contenido (Ørskov et al., 1988; Pinto de Carvalho et al., 2006).
La degradabilidad in situ tiene por objetivo proporcionar información del alimento referente a las fracciones solubles (a) y lentamente degradables (b), tasa de digestión y la degradabilidad potencial (DP) y efectiva (DE), así como las tasas de pasajes de 2, 5 y $8 \% / \mathrm{h}$ (Campos et al., 2011) y consumo (Araujo et al., 2010).

Los residuos de maíz chala (sin coronta) fresca o seca, la avena y la cebada, considerados como cultivos de invierno (época seca), son utilizados como fuentes principales de la dieta de los animales en la sierra peruana. Así mismo, se cuenta con residuos de la producción agrícola, como la raspa de papa y el salvado de trigo. No obstante, el conocimiento sobre la degradabilidad de la materia seca y de la proteína es escaso, por lo que es imperativo conocer la eficiencia con la que se extraen estos nutrientes durante la digestión.

En la formulación de las dietas de los animales se requiere la información relativa a las proporciones de las fracciones de los alimentos, así como de sus tasas de digestión (Veloso et al., 2000; NRC, 2001). Es así que los objetivos del presente trabajo fueron determinar la degradabilidad efectiva de la materia seca (MS) y de la proteína cruda (PC) por la técnica in situ y estimar el consumo de MS mediante ecuaciones de predicción referidas en la literatura del maíz chala fresco sin y con urea, de la cebada y avena como forrajes de invierno, y del salvado de trigo y de la raspa de papa. 


\section{Materiales Y MéTOdos}

\section{Ubicación del Estudio}

El experimento fue conducido en las instalaciones de la Escuela Académica Profesional de Zootecnia (EAPZ) de la Facultad de Ciencias de Ingeniería de la Universidad Nacional de Huancavelica. Los análisis de las muestras se realizaron en el Laboratorio de Nutrición Animal y Evaluación de Alimentos de la Facultad.

\section{Muestras y Tratamientos}

Se trabajó con maíz chala libre de mazorca, cebada y avena (cultivos de invierno) recogidos de áreas contiguas al Centro de Investigación Agropecuaria de Acraquia, ubicado en la provincia de Pampas, Tayacaja, Huancavelica, Perú.

Se preparó ensilado del maíz chala, con edad de 156 días. Para esto, se utilizó toda la planta, que fue cortada, picada manualmente con un machete en partículas de $5 \mathrm{~cm}$ y luego homogenizada. Se adicionó $1 \%$ de urea-sulfato de amonio (9:1), en base a materia natural. Se utilizaron cuatro bolsas de polietileno $(0.60 \times 0.90 \mathrm{~m}$ y con espesor de $0.20 \mathrm{~mm}$ ). El material fue presionado con la ayuda de un bastón de madera para facilitar la salida del aire. Las bolsas fueron cerradas con cintas adhesivas y almacenadas en un galpón con cubierta de madera. Asimismo, se preparó ensilado de maíz chala libre de urea utilizando el proceso descrito líneas arriba.

A los tres meses de la amonificación de la chala de maíz con urea, las bolsas fueron abiertas y aireadas por seis horas para permitir la liberación del exceso de amonio. Se tomó una muestra compuesta de $2 \mathrm{~kg}$, que fue pre-deshidratada en estufa de ventilación forzada a $65^{\circ} \mathrm{C}$ por 72 horas (Silva y Queiroz (2002).

La cebada y avena, como forrajes de invierno, fueron cortadas manualmente a $5 \mathrm{~cm}$ del suelo a la edad de 120 días de crecimiento, y trasladas de inmediato a las instalaciones de la EAPZ. Se les cortó en partículas de 2 a $3 \mathrm{~cm}$, con una picadora estacionaria (Maquiagro). Se tomaron cuatro muestras de $500 \mathrm{~g}$, constituyendo una muestra compuesta homogenizada de cebada y de avena. De cada uno de estos forrajes se obtuvieron muestras de $1200 \mathrm{~g}$, las mismas que fueron pre-deshidratadas al igual que el maíz chala.

El salvado de trigo (afrechillo) se obtuvo de centros de procesamiento de granos (molinos) y la raspa de papa se adquirió de agricultores que procesan este tubérculo en la forma seca. Para los propósitos de predeshidratación se consideró una muestra de $1200 \mathrm{~g}$ de cada uno de estos alimentos.

Una vez pre-deshidratados, los forrajes fueron convertidos en partículas de $3 \mathrm{~mm}$ y los alimentos concentrados en partículas de $2 \mathrm{~mm}$, con la ayuda de un molino de cuchillas para el ensayo de degradabilidad.

\section{Degradabilidad in situ en Alpacas}

Se utilizaron dos alpacas Huacaya machos, de dos años y peso vivo medio de 60 $\mathrm{kg}$. Los animales portaban cánulas en el primer comportamiento del aparato digestivo y se encontraban estabulados en corrales individuales de $3 \times 2 \mathrm{~m}$ que disponían de comedero y bebedero.

Los animales fistulados fueron alimentados con forraje de una asociación de ryegrass (Lolium multiflorum Lam) con trébol blanco (Trifolium repens L) y heno de avena (Avena sativa $\mathrm{L}$ ) en la proporción de 50:50.

La degradabilidad de la MS y la PC de los alimentos en estudio fueron estimadas por la técnica in situ del saco del nylon. Las dimensiones de los sacos de monofilamento de poliéster fueron de $10 \mathrm{x} 15 \mathrm{~cm}$ y porosidad de 50 micras. Cada saco contenía $5 \mathrm{~g}$ de muestra (en base a MS). Los seis alimentos fueron incubados por duplicado en el primer 
compartimento gástrico de las dos alpacas y retirados a las $0,6,12,24,48$ y 76 h después de la incubación (Nocek, 1988). Los sacos conteniendo muestras del tiempo cero ( 0 ) no fueron incubados. Los sacos fueron retirados luego de cada tiempo de incubación e inmediatamente lavados con agua corriente. Cada animal fue considerado como una repetición.

Una vez lavados, los sacos fueron secados en estufa de ventilación forzada a $65{ }^{\circ} \mathrm{C}$ por $72 \mathrm{~h}$ para el análisis químico posterior. El porcentaje de degradación de la MS y de la PC, por tiempo de incubación, fue calculado con base a la proporción de alimento que resultó en los sacos después de la incubación.

La degradabilidad de los nutrientes de los alimentos fue calculada mediante la ecuación descrita por Ørskov y McDonald (1979): $\operatorname{Deg}(t)=a+b x(1-\exp (-c x t))$, donde Deg $(t)$ $=$ degradabilidad o desaparecimiento del nutriente (MS o PC ) del alimento (\%); $\mathrm{a}=$ fracción del alimento soluble en agua en el tiempo cero $(\%) ; b=$ fracción insoluble en agua, pero potencialmente degradable en determinado tiempo (\%); $\mathrm{c}=$ tasa de degradación potencialmente degradable $(\mathrm{b}) ; \mathrm{t}=$ tiempo de incubación (horas); $\mathrm{a}+\mathrm{b} \mathrm{d} \gg 100$.

Los parámetros no lineares a, b y c fueron estimados con el aplicativo Solver de Microsoft Excel (Fernández, 2002). La degradabilidad efectiva de la MS (DEMS) y de la PC (DEPC) en el primer estómago de la alpaca fue calculada por intermedio de la ecuación de Ørskov y McDonald (1979): DE $=\mathrm{a}+(\mathrm{b} \times \mathrm{c} / \mathrm{c}+\mathrm{k})$, donde $\mathrm{k}=$ tasa estimada de pasaje de las partículas en el estómago (los demás parámetros fueron descritos en la ecuación anterior). La degradabilidad efectiva de la MS y la PC fue estimada para cada alimento, considerándose la tasa de pasaje de sólidos por el estómago de la alpaca de 2 , 5 y $8 \% / h$, que puede ser atribuido a un nivel de consumo alimenticio bajo, medio y alto, según AFRC (1993).
Los valores de MS fueron obtenidos en estufa a $105^{\circ} \mathrm{C}$. La PC fue determinada por el método Kjeldhal, según la descripción de Silva y Queiroz (2002). Para las estimaciones del consumo de MS de los alimentos se utilizaron las ecuaciones descritas por Araujo et al. (2010):

$$
\begin{array}{ll}
- & \text { CMS }=-0.822+0.0748(\mathrm{a}+\mathrm{b})+40.7 \mathrm{c} \\
& (\text { Ørskov } \text { et al. }, 1988) \\
- & \text { CMS }=-1.19+0.035(\mathrm{a}+\mathrm{b})+28.5 \mathrm{c} \\
& \text { (von Keyserling y Mathison, 1989) } \\
-\quad & \text { CMS = - 8.286 + 0.266a + 0.102b }+ \\
& \text { 17.96c (Shem et al., 1995) }
\end{array}
$$

\section{Resultados y Discusión}

El comportamiento de los parámetros cinéticos de la fracción soluble $(a)$, fracción potencialmente degradable $(b)$, tasa de degradación de la fracción $b(c)$ y las degradabilidades efectivas (DE) de la MS de los alimentos, en el primer estómago de la alpaca, para las tasas de pasaje de 2,5 y $8 \% / \mathrm{h}$ son mostradas en el Cuadro 1. La DE de la MS para la tasa de pasaje de $5 \% / \mathrm{h}$ de 54.80 y $52.40 \%$ encontrada para el ensilado de maíz por Martins et al. (1999) y Lallo et al. (2003), con tasas de degradación de 1.10 y $3.60 \%$, respectivamente, fueron inferiores al valor observado (62.07\%) en el presente trabajo (Cuadro 2).

La MS del ensilado de maíz chala con urea degradó más rápido $(16.51 \% / \mathrm{h})$ que el ensilado libre de compuesto no nitrogenado $(12.57 \% / \mathrm{h})$, y el valor de la fracción soluble fue de $22.78 \%$. El valor observado de la DE fue de $59.37 \%$ a la tasa de pasaje de $5 \% / \mathrm{h}$, mientras que para solo ensilado de maíz chala fue de $62.07 \%$.

La cebada, como forraje verde, con relación al maíz chala con o sin urea presentó un valor más bajo para la fracción soluble (19.15\%), DE (58.79\% para la tasa de pasaje de $5 \% / \mathrm{h}$ ) y tasa de degradabilidad $(10.06 \% / \mathrm{h})$. Sin embargo, la fracción no degradable en el 
Cuadro 1. Estimación de los coeficientes a, b y c de las ecuaciones ajustadas para la degradabilidad potencial de la materia seca (MS) y proteína cruda (PC) de los alimentos, y la fracción no degradable (i)

\begin{tabular}{lcccc}
\hline \multirow{4}{*}{ Alimentos } & \multicolumn{4}{c}{ Coeficientes } \\
\cline { 2 - 5 } & $\mathrm{a}$ & $\mathrm{b}$ & $\mathrm{c}$ & $\mathrm{i}$ \\
& \multicolumn{4}{c}{ Degradabilidad de materia seca (MS) } \\
\hline Maíz chala & 21.74 & 56.36 & 0.1257 & $21.90^{*}$ \\
Maíz chala-urea & 22.78 & 53.45 & 0.1651 & 23.77 \\
Cebada & 19.15 & 59.36 & 0.1006 & 21.49 \\
Avena & 24.58 & 56.00 & 0.0851 & 19.42 \\
Salvado de trigo & 11.61 & 69.63 & 0.1464 & 18.76 \\
Raspa de papa & 18.66 & 55.23 & 0.1002 & 26.11 \\
\hline & $\mathrm{a}$ & $\mathrm{b}$ & $\mathrm{c}$ & $\mathrm{i}$ \\
& Degradabilidad de proteína cruda (PC) & \\
\hline Maíz chala & 24.82 & 39.93 & 0.0513 & 35.25 \\
Maíz chala-urea & 27.85 & 39.46 & 0.0422 & 32.69 \\
Cebada verde & 31.53 & 39.82 & 0.0745 & 28.65 \\
Avena verde & 24.51 & 47.66 & 0.1334 & 27.83 \\
Salvado de trigo & 40.74 & 43.51 & 0.0514 & 15.75 \\
Raspa de papa & 38.40 & 34.08 & 0.1064 & 27.52 \\
\hline
\end{tabular}

$* 100-(21.74+56.36)=21.90$

Cuadro 1 de la MS de la cebada fue 2.28 puntos porcentuales menor que el maíz chala con urea. Considerando el coeficiente $(c)=$ $10.06 \% / \mathrm{h}$, la cebada se caracteriza como un alimento de rápida degradación de la MS (Martins et al., 1999).

La avena, como cultivo de invierno, presentó $60.64 \%$ de DE de la MS, para la tasa de pasaje de $5 \% / \mathrm{h}$. La fracción soluble obtenida de $24.58 \%$ fue la más representativa entre los alimentos evaluados; sin embargo, su tasa de degradación $(8.51 \% / \mathrm{h})$ presentó un valor medio y una no degradabilidad de $19.45 \%$

Los valores de $(a),(b)$ y $(c)$ para la MS del salvado de trigo observados en el presente trabajo fueron muy diferentes a los obtenidos por Martins et al. (1999) de 61.50\%, $28.70 \%$ y $11.70 \% / \mathrm{h}$. Asimismo, el $63.52 \%$ de
DE de la MS fue inferior al valor de $80.40 \%$ reportado por Martins et al. (1999) para la tasa de pasaje de $5 \% / \mathrm{h}$. Sin embargo, para esta tasa, el valor observado en el presente trabajo se compara favorablemente con la DE $60.20 \% / \mathrm{h}$ verificado por Valadares Filho (1994). Las diferencias en DE podrían deberse a las variedades de trigo analizadas y al tipo de operación para la obtención del residuo.

Los parámetros de degradación de la MS de la raspa de papa también presentaron valores bajos para la fracción $(a)=18.66 \%$ y la fracción $(c)=10.02 \% / \mathrm{h}$, que coincide favorablemente con el valor de $10 \% / \mathrm{h}$ para la raspa de yuca (Martins et al., 1999). Este autor, no obstante, encontró $75 \%$ de DE para la raspa de yuca con la tasa de pasaje de $5 \% / \mathrm{h}$, cifra que resulta ser superior al $55.51 \%$ de DE observado para la raspa de papa. 
Cuadro 2. Degradabilidad potencial (DP), y efectiva o real (DE) de la materia seca (MS) y proteína cruda (PC) de los alimentos, estimada para las tasas de pasaje de 0.02 , 0.05 y $0.08 \mathrm{~h}^{-1}$

\begin{tabular}{|c|c|c|c|c|}
\hline \multirow{3}{*}{ Alimentos } & \multirow{3}{*}{$\begin{array}{l}\text { Degradabilidad } \\
\text { potencial } \\
\text { (Dp) }\end{array}$} & \multicolumn{3}{|c|}{$\begin{array}{c}\text { Degradabilidad efectiva (De) } \\
\text { Tasa de pasaje }(\% / \text { hora })^{\mathrm{a}}\end{array}$} \\
\hline & & 2 & 5 & 8 \\
\hline & & \multicolumn{3}{|c|}{ Materia seca (\%) } \\
\hline Maíz chala & $78.10^{*}$ & 70.37 & 62.07 & 56.19 \\
\hline Maíz chala- urea & 76.23 & 70.67 & 59.37 & 54.14 \\
\hline Cebada & 78.51 & 68.66 & 58.79 & 52.20 \\
\hline Avena & 80.58 & 70.48 & 60.64 & 54.23 \\
\hline Salvado de trigo & 81.24 & 72.88 & 63.52 & 56.64 \\
\hline \multirow[t]{2}{*}{ Raspa de papa } & 73.89 & 64.70 & 55.51 & 49.38 \\
\hline & & \multicolumn{3}{|c|}{ Proteína cruda (\%) } \\
\hline Maíz chala & 64.75 & 53.36 & 45.05 & 40.43 \\
\hline Maíz chala- urea & 67.31 & 54.62 & 45.91 & 41.48 \\
\hline Cebada & 71.35 & 62.94 & 55.37 & 50.75 \\
\hline Avena & 72.17 & 65.69 & 59.10 & 54.33 \\
\hline Salvado de trigo & 84.25 & 72.07 & 62.80 & 57.77 \\
\hline Raspa de papa & 72.48 & 76.09 & 61.59 & 57.86 \\
\hline
\end{tabular}

Cuadro 3. Estimaciones del consumo de materia seca (MS), según las ecuaciones de autores utilizadas para la estimación del consumo de la MS de insumos utilizados para la alimentación de rumiantes

\begin{tabular}{lccc}
\hline \multirow{2}{*}{ Alimento } & \multicolumn{3}{c}{ Consumo de MS MSg/día $^{1}$} \\
\cline { 2 - 4 } & $\begin{array}{c}\text { Ørskov et al. } \\
(1988)^{1}\end{array}$ & $\begin{array}{c}\text { Shem } \text { et al. } \\
(1995)^{2}\end{array}$ & $\begin{array}{c}\text { von Keyserling y } \\
\text { Mathison }(1989)^{3}\end{array}$ \\
\hline Ensilado maíz chala & 10.14 & 5.50 & 5.12 \\
Ensilado maíz chala- urea & 11.60 & 6.19 & 6.18 \\
Cebada & 9.14 & 4.66 & 4.42 \\
Avena & 8.67 & 5.49 & 4.05 \\
Salvado de trigo & 11.21 & 4.53 & 5.82 \\
Raspa de papa & 8.78 & 4.11 & 4.25 \\
\hline
\end{tabular}

${ }^{1} \mathrm{CMS}=-0.822+0.0748(\mathrm{a}+\mathrm{b})+40.7 \mathrm{c}$

${ }^{2} \mathrm{CMS}=-8.286+0.266 a+0.102 b+17.96 c$

${ }^{3} \mathrm{CMS}=-1.19+0.035(\mathrm{a}+\mathrm{b})+28.5 \mathrm{c}$ 
En el Cuadro 2 se encuentran los parámetros $(a),(b),(c)$ y las degradabilidades efectivas (DE) de la proteína cruda (PC) de los alimentos, en el primer estómago de la alpaca, para las tasas de pasaje de 2.5 y $8 \% / \mathrm{h}$. Los valores de la PC en la forma soluble $(a)$ fueron bajos para los ensilados de maíz chala sin y con urea $(24.82$ y $27.85 \%)$. Estos valores fueron menores a la fracción $(a)(39.5 \%)$ encontrado por Lallo et al. (2003), pero superiores al $62.60 \%$ reportado por Rossi et al. (1997) y al 61.50\% encontrado por Martins et al. (1999) para ensilado de maíz. Cabral et al. (2005), asimismo, observaron un valor de $46.74 \%$. Es posible que la mayor proporción de los valores de $(a)$ en los ensilados estén representados por los compuestos nitrogenados no proteicos $(\mathrm{CNN})$, atribuibles a la ocurrencia de hidrolisis de las fracciones de proteína durante la fermentación del ensilado (Van Soest, 1994; Martins et al., 1999; Cabral et al., 2002). Los valores de la fracción potencialmente degradable $(b)$ de la PC de los dos tipos de ensilados de maíz chala son similares, pero mayores que la fracción (a). Asimismo, ambos ensilados presentaron valores similares de $\mathrm{DE}$ en las tasas de pasajes de 2,5 y $8 \% / \mathrm{h}$, con tasas de degradación parecidos (media de $4.67 \% / \mathrm{h}$ ), caracterizándolos como forrajes de baja y lenta degradación de la PC.

La fracción (a) y DE para las tasas de pasajes de 2,5 y $8 \% / \mathrm{h}$ para la PC de la cebada fueron mayores que en los ensilados de maíz chala, y tomando en cuenta el $7.45 \% / \mathrm{h}$ de degradabilidad se le caracteriza como forraje de mediana degradabilidad. Así mismo, la PC de la avena presentó la mayor fracción potencialmente degradable $(b=47.66 \%)$ con relación a la fracción $(a)$, probablemente por su mayor contenido de fibra. Por la DE $(59.10 \% / \mathrm{h})$ a la tasa de pasaje de $5 \% / \mathrm{h}$ y la tasa de degradabilidad de $13.34 \% / \mathrm{h}$, se caracteriza a la avena como de alta y rápida degradación en el primer estómago de la alpaca.

Entre los alimentos evaluados, el salvado de trigo destacó en PC por la mayor pro porción de la fracción soluble ( $a=40.74 \%$ ). Además de una baja fracción indigestible (I $=15.75 \%$ ), presentó alta $\mathrm{DE}$ a las tasas de pasajes de 2 y $5 \% / \mathrm{h}$, con lenta degradación $(5.14 \% / h)$. Valadares Filho (1994) encontró para el salvado de trigo alta DE ruminal de la PC $(75.5 \%)$ a la tasa de pasaje de $5 \% / \mathrm{h}$; es decir, 12.7 puntos porcentuales más que en el presente trabajo. En esta línea de investigación, Martins et al. (1999) verificaron valores elevados para la fracción $(a)$ y DE de la PC. Es así que por la tasa de degradación de $15.50 \%$ /h y los demás parámetros se considera que la PC del salvado de trigo es de rápida y de alta degradación ruminal.

Las variaciones en la tasa de degradación ruminal $(a)$ pueden ser atribuidos a errores propios a la técnica in situ, referidos a la porosidad de los sacos, influjo y reflujo, tamaño de las partículas, variación de la contaminación microbiana y errores de pesado, que afectan las curvas de degradación y, consecuentemente, las tasas estimadas (Nocek, 1998).

Las tasas de pasaje de 2,5 y $8 \% / \mathrm{h}$ para la raspa de papa no mostraron grandes discrepancias en la DE de la PC. La tasa de degradación de la PC presentó el doble de degradación $(10.64 \% / \mathrm{h})$ que la del salvado de trigo y, por tanto, la proteína de este alimento se caracteriza como de rápida degradación en el primer estómago de la alpaca. El valor de la degradabilidad de la raspa de papa se aproxima al $12.80 \% / \mathrm{h}$ de la raspa de yuca observado por Martins et al. (1999). Teniendo en cuenta la rápida digestión de la PC, la utilización de este alimento debe ser concomitante al suministro de alimentos proteicos de rápida fermentación, como el salvado de soya y pasta de algodón, entre otros. Según Russell et al. (1992), citado por Cabral et al. (2005), esta práctica permitiría reducir las posibles pérdidas de $\mathrm{N}$ del estómago de la alpaca o del rumen del vacuno, como resultado de la falta de sincronización de $\mathrm{N}$ y energía, cuando los animales son exclusivamente alimentados con forrajes. 
Los consumos de MS de los alimentos estimados por las fórmulas de Shem et al. (1995) y von Keyserling y Mathison (1989) fueron semejantes entre sí, a diferencia de las estimaciones resultantes con la fórmula de Ørskov et al. (1988) (Cuadro 3).

\section{Conclusiones}

- Entre los forrajes evaluados, la avena destaca por la elevada fracción $(a)$ de la materia seca y la mayor degradabilidad efectiva de la proteína cruda a las tasas de pasajes estudiadas, contrariamente a los demás forrajes cuya degradabilidad efectiva fue en media de $48 \% / \mathrm{h}$.

- En los alimentos concentrados, el salvado de trigo fue el más relevante por la mayor degradabilidad potencial de la materia seca y la menor fracción indigestible de la proteína cruda, en contraposición a la raspa de papa.

- Las ecuaciones sugeridas por Shem et al. (1995) y von Keyserling y Mathison (1989) permitieron la estimación de valores similares del consumo de materia seca por las alpacas.

\section{Agradecimientos}

Se agradece a los fondos de FEDU del vicerrectorado de investigación y a los fondos FOCAM del Proyecto «Evaluación de la siembra de avena y cebada asociado a la vicia y conservar el forraje para la alimentación de alpacas en las zonas altoandinas en el distrito de Huancavelica, provincias de Huancavelica, Castrovirreyna y Huaytara de la región Huancavelica» de la Universidad Nacional de Huancavelica, por el apoyo brindado en la realización de esta investigación.

\section{Literatura Citada}

1. [AFRC] Agricultural and Food Research Council. 1993. Technical Committee on Responses to Nutrients: energy and protein requirements of ruminants. Wallingford: Commonwealth Agricultural Bureaux International. $159 \mathrm{p}$.

2. Araújo SA, Maldonado VH, Coelho da Silva JF, Deminicis BB, Campos $P$, Lista F. 2010. Degrada«ão ruminal e estimativa de consumo de genotipos de capim-elefante añao. Rev Bras Zootec 39: 18-24. doi: 10.1590/S1516-35982010000100003

3. Cabral LS, Valadares Filho SC, Zervoudakis DJ, Pereira O, Veloso R, Pererira E. 2002. Cinética ruminal das frações de carboidratos, produção de gás, digestibilidade in vitro da matéria seca e NDT estimado da silagem de milho com diferentes proporções de grãos. Rev Bras Zootec 31: 2332-2339. doi: 10.1590/S1516-35982002000900023

4. Cabral LS, Valadares Filho SC, Zervoudakis JT, Lima de Souza A, Detmann E. 2005. Degradabilidad in situ de la matéria seca, da proteína bruta e da fibra de alguns alimentos. Pesq Agropec Bras 40: 777-781. doi: 10.1590/ S0100-204X2005000800007

5. Campos MM, Borges ALCC, Lopes FCF, Pancoti CG, Reis e Silva R. 2011. Degradabilidade in situ da cana-deaçucar tratada ou não com óxido de calico, em novilhas leiteiras Holandês $\mathrm{x}$ Gir. Arq Bras Med Vet Zootes 63: 14871492. doi: 10.1590/S0102-09352011000600028

6. Fernández HH. 2002. Un procedimiento simple para estimar parámetros de funciones útiles en producción animal, usando Solver de Excel. Rev Argentina Prod Anim 24: 75-81.

7. Gomide JA. 2004. Os volumosos na alimentação de vacas leiteiras. En: Nutrição de bovinos. Conceitos básicos e aplicados. $5^{\text {th }}$ ed. Piracicaba: FEALQ. 563 p.

8. Lallo FH, Prado IN, Nascimento WG, Zeoula L, Moreira F, Wada F. 2003. Níveis de substituição da silagem de milho pela silagem de resíduos industriais de abacaxi sobre a degradabilidade ruminal em bovinos de corte. Rev Bras Zootec 32: 719-726. doi: 10.1590/S151635982003000300024 
9. Martins AS, Zeoula LM, Prado IN, Martins EN, Loyola VR. 1999. Degradabilidade ruminal in situ da matéria seca e proteína bruta das silagens de milho e sorgo e de alguns alimentos concentrados. Rev Bras Zootec 28: 1109-1117. doi: 10.1590/S151635981999000500029

10. Nocek JE. 1988. In situ and other methods to estimate ruminal protein and energy digestibility: a review. J Dairy Sci 71: 2051-2069. doi: 10.3168/jds.S00220302(88)79781-7

11. [NRC] National Research Council. 2001. Nutrients requirements of dairy cattle. $7^{\text {th }}$ ed. Washington DC: National Academy Press. 381 p.

12. Orskov ER, Mcdonald I. 1979. The estimation of protein degradability in the rumen from incubation measurements weighted according to rate of passage. J Agri Sci 92: 499-453. doi: 10.1017/ S0021859600063048

13. Orskov ER, Rejo GW, Kay MR. 1988. Prediction of intake of cattle from degradation characteristics of roughages. Anim Prod 46: 29-34. doi: 10.1017/S000335610000307X

14. Rossi P, Silva AG, Wanderley RC, Bose M, Boin C. 1997. Degradabilidade ruminal da matéria seca e da fração protéica da silagem de milho, do farelo de soja e do sorgo em grão, em bovinos da raça Nelore. Comparação com os dados obtidos pelo CNCPS. Rev Bras Zootec 26: 599-607.

15. Russell BJ, O'Connor JD, Fox DJ, Van Soest PJ, Sniffen CJ. 1992. A net carbohydrate and protein system for evaluating cattle diets: I. ruminal fermentation. J Anim Sci 70: 3551-3581.
16. Shem MN, Orskov ER, Kimambo AE. 1995. Prediction of voluntary dry-matter intake, digestible dry-matter intake and growth rate of cattle from degradation characteristics of tropical foods. J Anim Sci 60:65-74. doi: 10.1017/S1357729800008146

17. Silva DJ, Quiroz AC. 2002. Análise de alimentos: métodos químicos y biológicos. Minas Gerais, Brasil: Universidade Federal de Viçosa. 235 p.

18. Spíndola GB, Azevedo AR, De Souza OD, Santana YAG, Moreira Filho MA, Moura Reis JA. 2016. Efeito de tamanho de particula sobre a degradação ruminal do feno do restolho da cultura do girasol. Rev Bras Cien Vet 23: 76-80. doi: $10.4322 / \mathrm{rbcv} .2016 .034$

19. Valadares Filho SC. 1994. Utilização da técnica in situ para avaliação dos alimentos. En: Simpósio Internacional de Produção de Ruminates. Brasil.

20. Van Soest PJ. 1994. Nutritional ecology of the ruminant. Ithaca, USA: Cornell University Press. 476 p.

21. Van Soest PJ, Mertens DR, Deinum B. 1978. Preharvest factors influencing quality of conserved forage. J Anim Sci 47: 712-720. doi: 10.2527/jas1978.$473712 \mathrm{x}$

22. Veloso CM, Rodríguez NM, Sampaio IBM, et al. 2000. $\mathrm{pH}$ e amônia ruminais, relação folhas: hastes e degradabilidade ruminal da fibra de forrageiras tropicais. Rev Bra Zootec 29: 871-879. doi: 10.1590/S1516-35982000000300033

23. Von Keyserlingk MAG, Mathison GW. 1989. Use of the in situ technique and passage rate constants in predicting voluntary intake and apparent digestibility of forages by steers. Can J Anim Sci 69: 973-987. doi: 10.4141/cjas89-112 